\title{
BMJ Open Quality 'We tend to get pad happy': a qualitative study of health practitioners' perspectives on the quality of continence care for older people in hospital
}

\author{
John Percival (D , ${ }^{1}$ Katharine Abbott, ${ }^{2}$ Theresa Allain, ${ }^{3}$ Rachel Bradley, ${ }^{4}$ \\ Fiona Cramp, ${ }^{1}$ Jenny L Donovan, ${ }^{5}$ Candy McCabe, ${ }^{1}$ Kyra Neubauer, ${ }^{2}$ \\ Sabi Redwood, ${ }^{6,7}$ Nikki Cotterill (1) ${ }^{1}$
}

To cite: Percival J, Abbott K, Allain T, et al. 'We tend to get pad happy': a qualitative study of health practitioners' perspectives on the quality of continence care for older people in hospital. BMJ Open Quality 2021;10:e001380. doi:10.1136/ bmjoq-2021-001380

Received 4 February 2021 Revised 19 March 2021 Accepted 24 March 2021
Check for updates

(c) Author(s) (or their employer(s)) 2021. Re-use permitted under CC BY-NC. No commercial re-use. See rights and permissions. Published by BMJ.

For numbered affiliations see end of article.

Correspondence to Dr John Percival; john.percival@uwe.ac.uk

\section{ABSTRACT}

Background Bladder and bowel control difficulties affect $20 \%$ and $10 \%$ of the UK population, respectively, touch all age groups and are particularly prevalent in the older (65+ years) population. However, the quality of continence care is often poor, compromising patient health and well-being, increasing the risk of infection, and is a predisposing factor to nursing and residential home placement.

Objective To identify factors that help or hinder good continence care for patients aged 65 years and over in hospital medical ward settings. Medical care, not surgical, was our exclusive focus.

Methods We conducted 27 qualitative interviews with nursing, medical and allied health practitioners in three hospitals. We used a purposive sample and analysed data thematically, both manually and with the aid of NVivo software.

Results Interviews revealed perspectives on practice promoting or inhibiting good quality continence care, as well as suggestions for improvements. Good continence care was said to be advanced through personcentred care, robust assessment and monitoring, and a proactive approach to encouraging patient independence. Barriers to quality care centred on lack of oversight, automatic use of incontinence products and staffing pressures. Suggested improvements centred on participatory care, open communication and care planning with a higher bladder and bowel health profile. In order to drive such improvements, hospitalbased practitioners indicate a need and desire for regular continence care training.

Conclusions Findings help explain the persistence of barriers to providing good quality care for patients aged 65 years and over with incontinence. Resolute continence promotion, in hospitals and throughout the National Health Service, would reduce reliance on products and the accompanying risks of patient dependency and catheter-associated gram-negative bacteraemia. Robust assessment and care planning, open communication and regular continence care training would assist such promotion and also help mitigate resource limitations by developing safer, timeefficient continence care.

\section{INTRODUCTION}

Continence care is a fundamental aspect of health service provision and has a substantial impact on individuals and the National Health Service (NHS). ${ }^{1}{ }^{2}$ Over 14 million adults in the UK experience involuntary loss of urine and 6.5 million have bowel control difficulties. ${ }^{3}$ Incontinence disproportionately affects older people, although older age is not a determining factor. ${ }^{4}$ Incontinence is more common than heart disease, breast cancer or diabetes among older women, yet its public health profile is undeveloped, demoting its importance and quality assurance safeguards. ${ }^{5}$

Incontinence brings significant personal and public costs. Quality of life can be reduced by isolation, anxiety, loneliness and depression, with self-esteem undermined by decreased independence, mobility and health. ${ }^{3}$ Furthermore, older people are commonly too embarrassed to seek help and may reduce food and fluid intake, along with social contact and activity, so as to mitigate continence 'accidents'. ${ }^{78}$ Annual continence care costs to the NHS have risen from $£ 77$ million in $2006 / 2007$ to over $£ 200$ million in $2010 / 2011,^{9}$ with more recent data difficult to ascertain. Catheter-associated urinary tract infections are estimated to cost the NHS up to $£ 99$ million per year, while pressure ulcers, often caused by poor care associated with incontinence, cost the NHS between $£ 1.4$ and £2.1 billion annually. ${ }^{10}$ Additionally, inadequate management of incontinence can escalate costs resulting from morbidity, unnecessary and sometimes lengthy hospitalisation, and raised mortality rates. ${ }^{9} 10$

The quality of continence care has been under scrutiny in recent years, with relevant guidance advocating early assessment and identification of symptoms, together 
with initial conservative management and individualised care. ${ }^{11} 12$ Treatment of incontinence, however, has been found to be inadequate, ${ }^{13} 14$ particularly for older adults. ${ }^{1516}$ Falls, pressure ulcers and moisture lesions are directly linked to poor continence care in older adults. ${ }^{17}$ National audits and guidance regarding continence care have identified that healthcare professionals in acute care settings inconsistently identify, assess, manage and treat incontinence.$^{18-20}$ The Francis public inquiry report referred to continence as 'this most basic of needs' and yet it was the area of care most frequently singled out for complaint. ${ }^{21}$ Reports have also raised concern in respect of insufficient staff support and education, weak service integration and liaison, inconsistent care planning and poor communication regarding continence care. ${ }^{1320}$

An over-reliance on certain products, such as incontinence pads and catheters, has also compromised the quality of continence care. Between $17 \%$ and $25 \%$ of patients in acute care have an indwelling urinary catheter, of which at least a quarter are unnecessary. ${ }^{22}$ Moreover, $60 \%$ of urinary tract infections relate to catheter use and almost one-third of medical and surgical inpatients are inappropriately treated with catheters. ${ }^{92}$ Incontinence pads are sometimes not the right type or size, which can affect patient hygiene, skin integrity and dignity. ${ }^{7}$ Nurses often rely on containment methods, such as pads, indwelling catheters and penile sheaths, rather than help patients maintain continence. ${ }^{9}{ }^{23}$ Training programmes on continence care are available but these are delivered in less than half of acute hospitals, ${ }^{11} 1315$ perhaps because of the low priority placed on this fundamental aspect of care. $^{5}{ }^{18}$ Additionally, staff requiring help or advice in respect of continence care practice are unlikely to have access to local specialist nurses or services, ${ }^{13}{ }^{18}$ despite such provision having been strongly advocated in recent years. ${ }^{9}$

There is a clear need for improved continence care in the NHS, ${ }^{24}$ together with a better understanding of healthcare workers' perspectives, across disciplines and grade levels, as evidence is limited in this respect. ${ }^{152021}$ The aim of our study was to address these points by conducting in-depth interviews with nurses, doctors and allied health practitioners, in order to learn details of factors that help or hinder appropriate continence care for older adults in hospitals and perceived improvements to optimise care.

\section{METHODOLOGY}

\section{Patient and public involvement}

In 2019 NC (chief investigator) held two engagement events that brought together over 60 patients, carers and the public, as well as multidisciplinary healthcare staff from varied settings. The aim was to unpick the priorities for continence care and identify routes to improvement. A vital gap highlighted was care provided in hospitals and the perceived low priority of continence care. Our study was borne out of this patient and public engagement and the importance attached to understanding influences on the provision of continence care in order to identify improvements. A patient and public involvement (PPI) group led by NC contributed to the overall study design and focus of investigation. PPI partners were unable to be involved in recruitment of the participants as the latter were healthcare professionals. However, PPI partners influenced the breadth of professions prioritised for inclusion in the study and the decision not to limit participant inclusion to the nursing profession alone. An infographic will be produced to disseminate high-level findings to study participants and the PPI group involved, with the full study report also made available.

\section{Study design and participant recruitment}

A qualitative design was adopted, using semistructured interviews with hospital-based nursing, medical and allied health professional staff, of varying grades, to explore perspectives on the obstacles and challenges to evidencebased continence care and ways to optimise such care on medical wards. The interview schedule, designed for the study, was informed by previous audit data and existing evidence $\mathrm{e}^{25}$ and reviewed by all authors. The main inclusion criterion was that research participants have responsibility for patients aged 65 years and over. Recruitment was carried out through purposive sampling of staff groups to achieve representation across professional roles. Research participants were recruited in acute inpatient wards (mostly, though not exclusively, care of the elderly wards) at three hospitals in the South West of England. These sites were selected to represent two large, city teaching hospitals, (one with specific responsibility for urology services) and one was a smaller, nonteaching centre. The lead researcher (JP) met with ward managers at each hospital to explain the research and provide participant information materials for display and distribution among staff. Representation from each staff group, nursing, medical and allied health was achieved and the sample size determined during ongoing analysis and interpretation of emerging themes, ensuring data saturation in line with the study's aims. One-off individual interviews ranged in length between 25 and $55 \mathrm{~min}$ and averaged 30-minute duration. These interviews took place in hospital and were carried out by JP. The interview topic guide was designed to elicit participants' perceptions and experiences regarding identification and management of continence care needs, availability and provision of relevant education, and factors promoting or hindering good quality continence care.

\section{Data analysis}

Interviews were audio recorded, transcribed verbatim, and subject to thematic and content analysis. ${ }^{26}$ Initial analysis involved close reading by JP of each transcript, at least twice, providing an opportunity for development of coding strategies in relation to emerging subject domains, themes and subthemes. Transcript data were then imported into the qualitative data management software package NVivo V.12, which assisted in the 


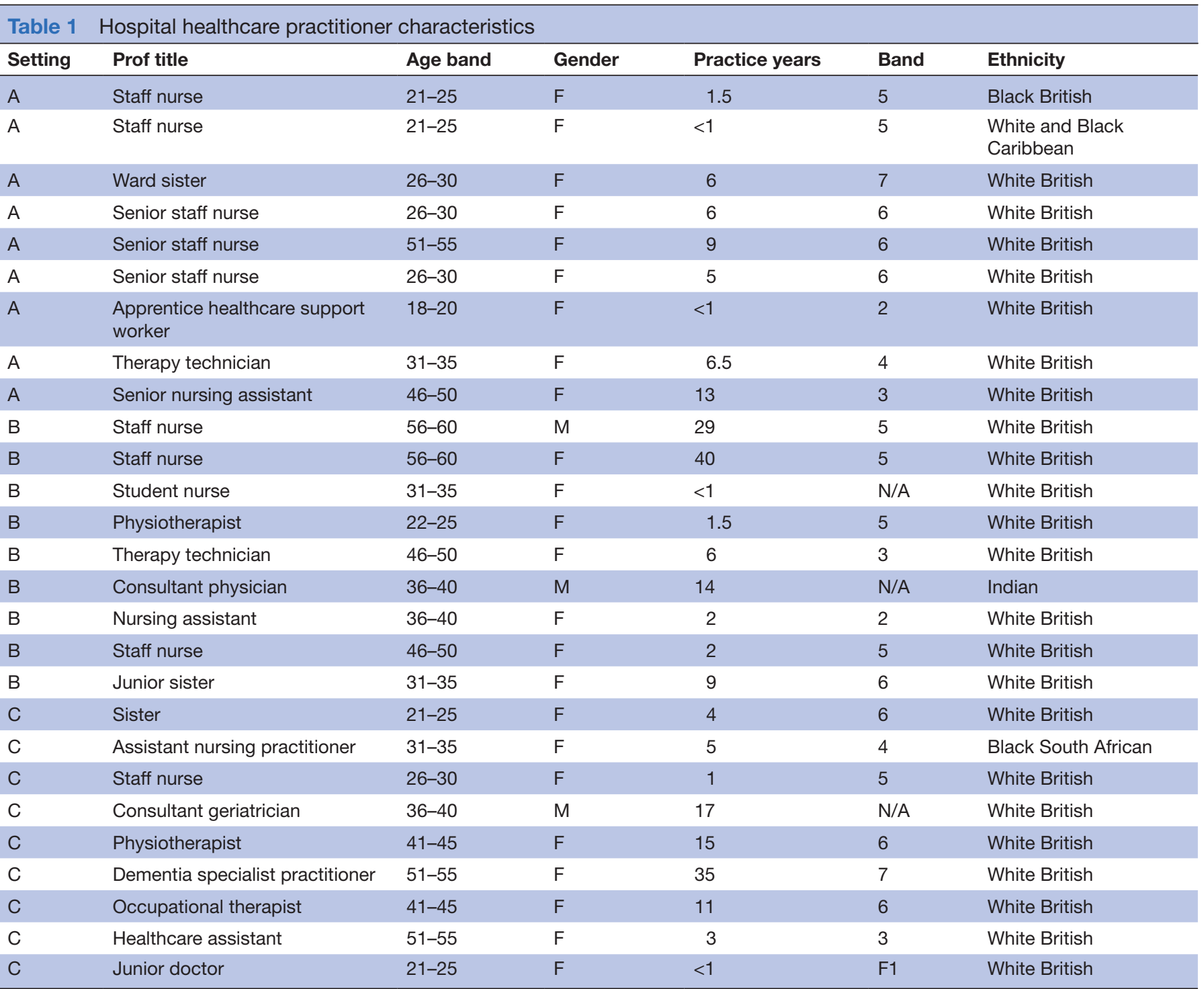

N/A, not available.

organisation and linkage of segments of text and the examination of relationships between themes. ${ }^{27}$ Coding was further refined by JP and the chief investigator (NC) using a coding frame devised to highlight theme connectivity and relevance to the primary areas of investigation. The conduct and thematic outcomes of analysis were considered and agreed on by all authors.

\section{RESULTS}

A total of 27 participants was evenly spread across the three hospital sites, as shown in table 1 . This total included 17 nursing staff, 5 allied healthcare professionals, 3 medical staff and 2 healthcare assistants.

The data reflected only slight differences in emphasis according to professional role, with no markedly divergent opinions arising. Key themes that emerged are therefore representative of all participants' perspectives and concerns. These themes are: practice promoting good quality continence care; obstacles to good practice and suggestions for improvements.

In order to safeguard confidentiality, the source of each participant interview excerpt included in this paper is identified using a letter signifying each hospital site, as shown in table 1 , followed by the practitioner's study identification number.

Practice promoting good quality continence care

Participants gave accounts of the constructive ways in which they addressed older patients' continence care needs, especially through: routine assessment and monitoring; forward planning; person-centred care and encouragement of independence.

Routine assessment and monitoring

While incontinence was rarely the over-riding reason for a patient's admission, it was said by most of our interviewees to be an issue that featured prominently in their everyday practice, as suggested by its description a consultant 
physician as 'one of the geriatric giants' (B46). Incoming patients' incontinence was often said to accompany multimorbidity: mobility problems, frailty, prolapse consequences, diarrhoea, mental illness or a degenerative condition, such as Parkinson's. Practitioners were equally aware that a patient's incontinence may have been aggravated by the condition's poor management prior to admission.

Notwithstanding this backdrop, the commonly used pro-forma hospital admission assessment procedures were said to insufficiently capture continence care needs, due to 'variable' or sometimes 'incomplete' detail. As a result, staff strove to gather detailed understanding in their ongoing work on the wards, through routine checks of skin condition, temperature and urine/faecal output, and when possible, in discussion with patients and family members:

If I am doing an assessment of someone and their dementia, I would be asking questions around their continence and how they are managing to get to the bathroom...Are they normally continent at home, do they wear pads?... so it's trying to make sure that full assessment is done in hospital... so we don't make things worse for that person while they are an inpatient. (C26, dementia specialist practitioner)

Routine investigation also helped practitioners establish when incontinence pads could be dispensed with in favour of regular toileting, as well as the need for, and potential problems of, catheter use.

\section{Forward planning}

Participants told us the hospital environment could inhibit patients talking about their incontinence because they were embarrassed and feared drawing attention to themselves in this semipublic space. A nursing assistant emphasised the value of being proactive through paying close attention to patients who also have difficulty articulating their continence care needs:

Those patients [with dementia] you need to be a lot more proactive with... encouraging them to use the bathroom at those key times when they get out of bed first thing in the morning, before they go to bed, before lunches, before dinners. I think they feel more comfortable and happy in the hospital if they are not having to ask to go to the toilet. (B47, nursing assistant)

Planning ahead was also important to a physiotherapist (B44), who commented that in the course of her work with catheterised patients who had restricted mobility, she strove to get a trial without catheter (TWOC) procedure (commonly referred to as 'TWOC'd') undertaken 'early', as this could help motivate patients to increase mobility as well as offset the risk of patients returning home still catheterised.

\section{Person-centred care}

According to one participant, nursing staff should aim to be fully aware of continence care issues 'because we are taught to look at the patient holistically' (A06, staff nurse). Examples of person-centred care include a staff nurse (B42), who told of her work with catheterised patients with dementia whose psychological need to use the toilet was respected, and a nursing assistant (C22), who interpreted a patient's change in behaviour as a 'communication tool' alerting her to his urine retention. A physiotherapist, describing her role in helping a patient recover balance and mobility skills, said she used toileting as a motivational strategy because this goal was the patient's own mental 'priority'.

Underpinning these approaches to continence care was a commitment to building a rapport with patients, so that patients could confidently communicate their needs, in itself confirmation of good continence care practice:

If your patient...can ask you to use the toilet, I feel like you are being a very good nurse. And [if] they feel like they can tell you if they need changing, I feel like you are being a very good nurse. (C21, ward sister)

\section{Encouragement of independence}

On all hospital wards included in the study, the ambition to help older patients with incontinence 'get back' to their original 'baseline' or 'as independent as possible' was commonly reported by participants to be a primary objective in caregiving. An important strategy in this respect was enabling less mobile to transfer more readily to the toilet, activity that appealed to notions of normality and was motivational, physically strengthening and positively impacted patients' mental health. In addition, such practice was said to be time-efficient:

If their continence improves by emptying their bladder and bowel [on the toilet rather than commode] and they feel a lot better because they have sat up [in privacy] in a good position, then they are going to have less interventions for their incontinence. (C25, physiotherapist)

\section{Obstacles to good practice}

Notwithstanding participants' positive accounts described above, it was clear from interviews that hospital practitioners faced certain barriers to providing good, consistent, continence care. In particular, participants highlighted: lack of oversight, over-reliance on incontinence products and staffing pressures.

\section{Lack of oversight}

Participants pointed out that information gained from monitoring patients' continence care was only useful if accurately and routinely recorded and, as this was not always the case, such information could not be relied on:

This morning a lady was TWOC'd...she is mobile, gone to the toilet a couple of times last night but nobody has documented to see if she has passed urine or not or how much. (A04, senior nursing assistant) 
Interviewees also speculated that this laxity arose because of a tendency not to notice, or take stock of, the commonplace:

Continence care is an important area and the only thing I find is because it's such basic care, it gets overlooked and forgotten about at times... some [staff] think there is nothing to worry about. But I think they should do. (B41, staff nurse)

A ward sister concurred that continence care is 'forgotten about', claiming because other procedures and tasks are seen as more important, with the result that patients are 'kept in pads' by unquestioning staff or are sent home with catheters that are not necessary. A dilatory attitude could also preclude consideration of proactive continence care strategies. In this respect a dementia specialist practitioner described how when she advised staff to engage in regular 2-hour toileting routines, to keep patients dry and stop them becoming agitated, she was sometimes viewed 'as though I have got snakes coming out of my head. It's an old fashioned concept but it works' (C26).

\section{Over-reliance on incontinence products}

The use of pads, without due regard to the possible health implications, led one nursing assistant to worry that this could 'encourage incontinence and becomes an obstacle to keeping people continent' (B47). A ward sister echoed this point when she drew the conclusion, 'We cause incontinence a bit' (C21). In addition to the question of staff inattention, discussed above, participants suggested a number of intrinsic reasons for over-reliance on products: custom and practice, expediency and patient acceptance.

Custom and practice in respect of pad over-reliance was implied by many interviewees when speaking of pads being provided as a matter of course, without first determining need, suitability, benefit or risk. This convention was summed up by one staff nurse when admitting, 'we tend to get pad happy' (C23). A nursing assistant added weight to this concern by pointing out that 'registered nurses should prescribe continence products [but] it's very rare that I have seen that done' (B47), leaving her and her peers to make these clinical decisions.

Expediency, given staffing levels and pressures on time, was another reason for over-reliance on pads. A physiotherapist spoke of nurse colleagues being 'always up against the clock [so] it's easier just to stick a pad on someone [and] not allow them to walk to the toilet' (C25). Although expediency was most often talked about in relation to over-reliance on pads, it was also said to contribute to overuse of catheters. Unnecessary provision of catheters was said to occur as a service convenience or because staff were too busy to review their use. A junior doctor noted that over-reliance on catheters and delay in their removal 'can be a very common situation' (C29).

Patients themselves were said to be, on occasion, complicit in the routine use of products such as incontinence pads, by accepting pads in order to reduce the burden on obviously overstretched staff. As one staff nurse put it, 'they don't want to bother the nurse'. Another reason for patients' assent in the regular use of pads was said to be anxiety and embarrassment about their incontinence, which could lead to dependency on pads as a method of masking their incontinence in a semipublic environment. An important consequence of product over-reliance was reported to be the weakening of patient independence and fostering of dependency.

\section{Staffing pressures}

A senior staff nurse (A01) referred to the benefit of having secured an extra nursing assistant to help patients with toileting but added that with the heavy workload on the ward, 'we are still struggling'. The general pressure that hospital staff were under led one consultant geriatrician to reflect how older patients' incontinence needs could be missed if they were not highlighted by the patient, adding 'the pressures on hospital are to treat the primary condition and get them out... we don't pick up [continence needs] as much as we could do because it's not the thing that's flagged up in front of you' (C24). Other staff agreed that key indicators of continence need could easily be overlooked, with one staff nurse saying by way of example, 'this patient might not have wee'd for an hour or two and urine output might have tailed off [which] might be missed' (A06).

These concerns were often reinforced by reference to low staff to patient ratios, especially problematic on wards where many patients were bedbound or recovering from surgery, requiring two members of staff to support them with their needs.

\section{Suggested improvements}

Participants' ideas on improvements to continence care practice coalesced around four issues: participatory care, open communication, robust planning and staff training, the latter assuming prominence throughout interviews because of its potentially beneficial influence on the other desired improvements. These issues are represented in figure 1, which depicts four desired improvements, on the left, and two likely outcomes of these improvements, circled on the right.

\section{Participatory care}

Interviewees talked of wishing to enable greater patient independence and management of their continence, thereby helping mitigate 'institutionalised' and 'dependent' behaviour. This, they said, would best be achieved through a facilitative approach based on participatory care, both in respect of product use and mobilising to use the toilet:

I think we are all very well meaning as a profession but I do think we put an onus on people being dependant on us. You know, "it's OK, I will come and wash you my lovely". No! Put a bowl there, let them do it themselves! Get them walking out to the toilet, get a commode by the side of them, do what it takes... we 


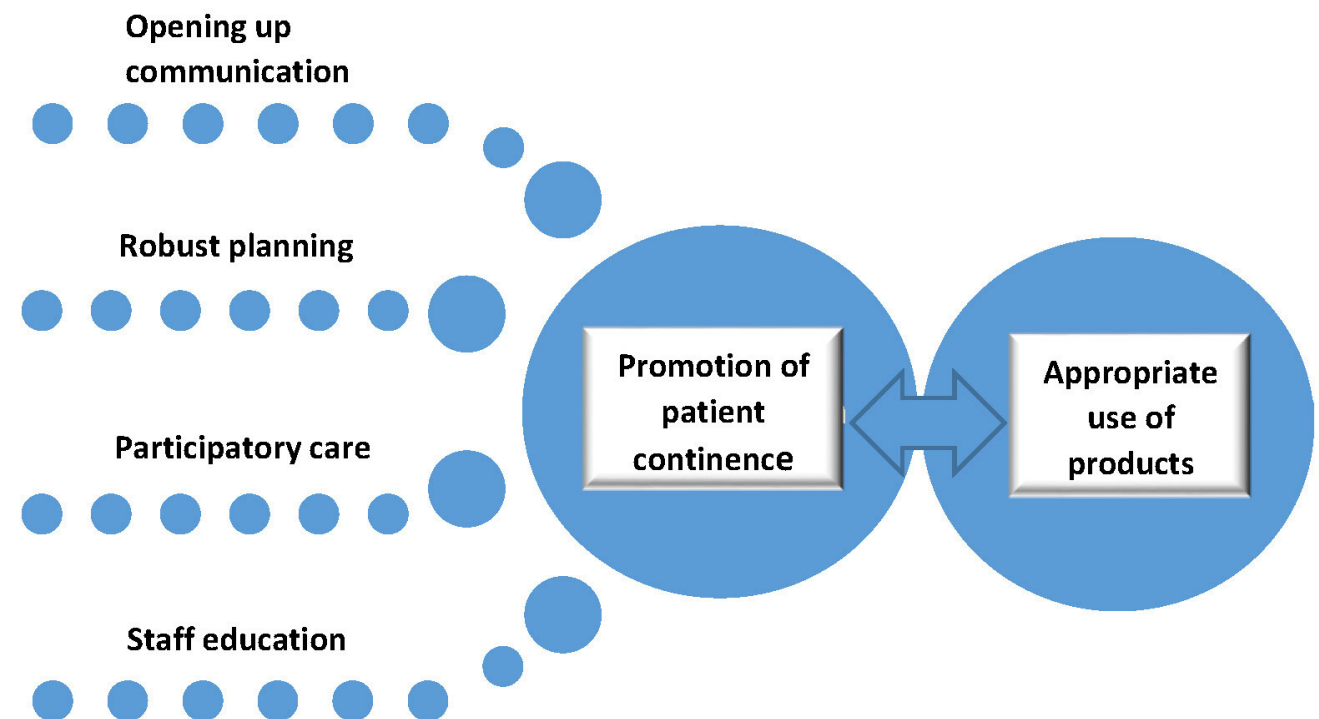

Figure 1 Suggested improvements to continence care practice and related outcomes. The four statements on the left depict participants' desired improvements, which, if enacted, percolate to produce the two likely outcomes in the circles on the right.

need to look at that and say, "right, we are managing your care but I need you to be participating in your care and increase your independence so we can [better] meet your needs". (A09, senior staff nurse)

\section{Opening up communication}

Participants put forward the likely benefit of opening up, or broadening, their communication with, or about, patients with incontinence. A consultant geriatrician, admitting that faecal incontinence is 'a bit underrecognised', observed that 'we only uncover things when we ask about them [and] we are less good asking about bowel problems than we are about bladder problems' (C24). More generally, interviewees suggested that talking in a matter-of-fact way with older patients about incontinence would help overcome patients' reluctance to do so. Furthermore, attentive listening and opening up a dialogue so that patients, and where appropriate, family members, were better able to express their views would also allow staff to fine tune interventions to meet the individual's needs:

Some feedback from patients about how we can make them feel a bit more comfortable being incontinent would be good. Because sometimes you can go over to somebody and say its fine, don't worry. It would maybe nice to know how they would want us to approach it as opposed to [us] just batting it off. (A08, senior staff nurse)

\section{Robust planning}

Participants told us that continence care plans, where they existed, provided a useful guide 'so that everyone knows what the situation is and how it should be managed' (C25, physiotherapist). Interviewees added that to be effective, however, continence care planning had to be robust in terms of routine updating and forward thinking. Routine consideration of continence care needs would more likely take place, according to one consultant geriatrician, within an integrated appraisal system:

The thing that we have lost is proper old fashioned MDTs [multidisciplinary teams]... now you have a daily ward round where you catch up with everyone but continence [is missed] when you are nipping round quite quickly, whereas in the past I would do MDTs where we would routinely talk about skin care, continence, nutrition. We don't do that now. So having something where it was routinely discussed for everyone, that would help. (C24, consultant geriatrician)

A consultant physician also advocated a higher profile for continence care within 'intentional rounding' (B46). This sharper focus on continence care would, according to a staff nurse, facilitate forward planning and preventative work, with the corollary 'I think we can then avoid the need for catheters' (A09, senior staff nurse).

Participants also wished to see more proactive planning in regard to patient discharge and associated community liaison. Particular emphasis was put on improving referral procedures for district nursing regarding catheter care, in order to mitigate delays that were said to arise when discharge letters to general practitioners were not promptly acted on and to enable a better 'flow' of information to district nurses (B49).

\section{Staff training}

The majority of participants told us they had received no 'specific', 'formal' training in continence care but had learnt about it 'on the job', 'talking to colleagues' or 'just doing it'. This was a particular concern in regard to nursing and healthcare assistants, given that they often worked with 'high continence needs but haven't really had much training in it' and so may be unaware, for 
example, of 'the link between skin [integrity] and continence' (C23). Doctors also conceded 'we get very little [continence care] training... it's not high enough on our curriculum' (C24), and, 'if we did have [continence care] training we might be able to stop these situations when we have forgotten to TWOC the patient' (C29).

Participants believed continence care education would potentially have a pivotal impact on practice, improving staff awareness of relevant information, advice and best practice guidelines. Most importantly in the opinion of many participants, improved recourse to relevant education would help ensure proper, safe use of continence care products. Specific updates on incontinence pads would help provide 'awareness of why we are putting a pad on' (C27) as well as guidance on 'how to make sure [staff] have got the right size pad' (C29) and 'how often you change pads... we don't know' (B42). As regards catheters, a therapy technician suggested staff would benefit from 'teaching around... weighing up the effects of long-term catheter and short-term catheter [use]' (A03). Education would also help staff 'get rid of' incontinence sheets, which were in some cases still used inappropriately with incontinent patients and sometimes 'causes their skin to break down' (A01).

\section{DISCUSSION}

This study has drawn attention to incontinence as a demanding condition frequently encountered in the hospital setting, often accompanied by multimorbidity and exacerbated by poor continence management. Findings from our study help explain the prominence and persistence of certain barriers preventing appropriate continence care for older patients in hospital, as well as key opportunities for improvement in this setting.

Previous studies have highlighted the importance of assessment as a benchmark of appropriate continence care. ${ }^{58}$ The hospital practitioners we interviewed were certainly aware that ongoing assessment of patients with incontinence increases practitioners' understanding of the condition as well as the efficacy of particular treatment interventions. Additionally, findings reveal how practitioners were also mindful of proactive treatment strategies, arising from assessment, which promote good quality, safe, person-centred, care. Such strategies include early use of the TWOC procedure, scheduled toileting and prompted voiding. ${ }^{70}{ }^{23}$ That practitioners did not consistently succeed in achieving this level of evidencebased assessment and care management was certainly a consequence of resource and organisational factors that impacted on staff time and limited availability of specialist support and advice. ${ }^{18} 1924$ However, our study also underlines the importance of staff-patient communication to good quality continence care.

Indeed, practitioners knew that only when older patients feel they can safely discuss their continence difficulties and wishes will they have sufficient confidence to participate actively in mobilising, toileting and other aspects of the care process known to promote continence. ${ }^{15} 1928$ Furthermore, facilitative communication, we suggest, may help reduce patients' ready agreement to the use of incontinence pads, by openly addressing issues of embarrassment and reluctance to bother busy staff. In this context, future research could usefully investigate practitioner awareness of the potential for sensitive conversations to improve continence care, as commended with respect to other forms of healthcare. ${ }^{29}$ Studies have found that good communication is also a key component of well-integrated continence care within services and between hospital and relevant community agencies, although the quality of such communication is variable. $^{1620}$

When practitioners in this study spoke of wishing to help older patients regain continence and return to their normal level of independence, they were, to some extent, trying to offset what other studies have suggested is the patient's likely institutionalisation in the hospital environment and its corollary, greater patient dependency or deferment of independence. ${ }^{712}{ }^{24}$ In this respect an important strategy is encouragement of patients to mobilise, in order to use the commode or toilet, and reduction in the use of pads and catheters. Both these aims are shown, in our study, to be compromised by the interconnected obstacles of routine over-reliance on products and widespread shortages of hospital staff. ${ }^{14}{ }^{22}$ Product over-reliance was also identified in a recent Public Health England report exploring behaviours associated specifically with catheterisation. ${ }^{30}$ These barriers have significant consequences for patients' health and treatment, not least in respect of gram-negative bacteraemia infections, which are a national reduction priority. Indeed, the use of urinary catheters is strongly connected with urinary tract infections and the requirement to reduce catheterisation rates is recognised, and procedurally supported, by the NHS England HOUDINI protocol. ${ }^{31-33}$

Another national priority, led by the NHS England and NHS Improvement, is the reduction of pressure ulcers in the NHS. The 'Stop the Pressure' campaign is inextricably linked with improved continence care and underpinned by a national wound care strategy providing tools for NHS trusts to reduce incidence, thereby reducing harm and spiralling costs. Initial implementation achieved a $50 \%$ reduction in pressure ulcers ${ }^{34}$ and ongoing trust accountability ensures this area of care retains this level of priority. ${ }^{35}$ On the evidence of our findings, lessons can be learnt from the 'Stop the Pressure' campaign to identify the transferable strategic framework required to raise the profile and safeness of continence care.

Our study findings also indicate that increased training opportunities could positively impact procurement costs associated with reactive, product-focused continence care, when compared with proactive conservative interventions, such as regular toileting, increasing mobilisation and promoting independence. This shift in approach offers the prospect of a sharper focus on the judicious use of pads and catheters to safeguard patient health and 
independence, which in turn requires staff to confidently initiate open discussion with patients. Beyond the hospital episode, signposting to longer term continence promotion strategies such as bladder retraining and pelvic floor muscle training could also be achieved by well-informed inpatient staff who have identified continence issues that may not have previously been discussed. ${ }^{4}$ Our data also strengthen the argument for designated continence care lead personnel, currently lacking in many hospitals, to provide the authority and oversight to help ensure a commitment to regular staff training, as well as the improvement of staff adherence to good practice guidelines and relevant nurse proficiency standards. ${ }^{36} 37$ These advances would aim to raise the profile of continence care as an essential aspect of good quality healthcare, requiring more than rudimentary skills. ${ }^{5}$

The key strengths of the study include its targeted focus on the hospital setting, an environment comparatively under-researched in the context of continence healthcare practice. Furthermore, we included the perspectives of a range of practitioners, working at different levels in their profession. Importantly, in addition to contributing insights into ways to improve continence care in hospitals, the data we gathered help strengthen the health policy case to reduce the unnecessary use of products known to have adverse health consequences. A limitation of the study is that despite data gathering across three hospital sites, the sample size is relatively small and findings may not be generally transferable. Also, the balance of research participants was in favour of nursing staff and greater representation of medical staff and allied health practitioners would potentially have helped further refine interpretations of our research data.

\section{CONCLUSION}

Our study set out to establish a better understanding of health carer perspectives on the barriers and enablers of good quality continence care in the hospital setting. These findings will inform the debate on how continence care can be improved for patients aged 65 years and over. While participants were aware of the importance of good quality continence care, they identified a number of obstacles. The study identifies the mitigating effects of proactive care, effective practitioner-patient communication and robust assessment and care planning, underpinned by a commitment to provision of regular training. Such improvements, not overly complicated or costly, could help develop a system-wide approach to raising the profile of this fundamental aspect of care, bringing it in line with other essential areas of patient care and thereby delivering tangible benefits to individuals and the NHS.

\section{Author affiliations}

${ }^{1}$ Nursing and Midwifery, University of the West of England Faculty of Health and Applied Sciences, Bristol, UK

${ }^{2}$ North Bristol NHS Trust, Bristol, UK

${ }^{3}$ Department of Medicine for Older Persons, University Hospitals Bristol and Weston NHS Foundation Trust, Bristol, UK
${ }^{4}$ Department of Geriatric \& Orthogeriatric Medicine, University Hospitals Bristol and Weston NHS Foundation Trust, Bristol, UK

${ }^{5}$ Medical School, University of Bristol, Bristol, UK

${ }^{6}$ National Institute for Health Research Collaboration for Leadership in Applied Health Research and Care West (NIHR CLAHRC West), Bristol, UK

${ }^{7}$ Population Health Sciences, University of Bristol Medical School, Bristol, UK

Twitter Nikki Cotterill @NikkiC07

Acknowledgements We would like to thank the study participants for their valuable contributions and for sharing their views so openly. We are also grateful for the valuable patients and public contributions to the development of this study.

Contributors The entire authorship, including JP, KA, TA, RB, FC, JLD, CM, KN, SR and NC, contributed to the conception and design of the study, interpretation of the data, and drafting, revising and approving the final article. In addition, JP conducted all the data collection and analysis and NC assisted in the data analysis.

Funding This work was supported by the University Hospitals Bristol and Weston NHS Foundation Trust, Research Capability Funding (RCF) stream (grant number 2018-Aut-03).

\section{Competing interests None declared.}

Patient and public involvement Patients and/or the public were involved in the design, or conduct, or reporting, or dissemination plans of this research. Refer to the Methods section for further details.

Patient consent for publication Not required.

Ethics approval Interviews were carried out in accordance with research governance ethics protocols and with Health Research Authority (HRA) approval (UWE Research Ethics Committee reference: HAS.19.07.221). Written consent was provided by each participant prior to interview.

Provenance and peer review Not commissioned; externally peer reviewed.

Data availability statement Data are available upon reasonable request. Data, in the form of transcripts of interviews with healthcare professionals, are held on university servers and protected under GDPR guidelines and in accordance with ethical approval.

Open access This is an open access article distributed in accordance with the Creative Commons Attribution Non Commercial (CC BY-NC 4.0) license, which permits others to distribute, remix, adapt, build upon this work non-commercially, and license their derivative works on different terms, provided the original work is properly cited, appropriate credit is given, any changes made indicated, and the use is non-commercial. See: http://creativecommons.org/licenses/by-nc/4.0/.

ORCID iDs

John Percival http://orcid.org/0000-0002-0608-997X

Nikki Cotterill http://orcid.org/0000-0001-6921-2712

\section{REFERENCES}

1 NHS England. Excellence in continence care: practical guidance for commissioners, and leaders in health and social care. NHS, 2018. Available: https://www.england.nhs.uk/wp-content/uploads/2018/07/ excellence-in-continence-care.pdf [Accessed 13 Jan 2021].

2 James Lind Alliance. Incontinence: the taboo hurting the dignity and health of millions. James Lind alliance, 2018. Available: http://www. jla.nihr.ac.uk/news/incontinence-the-taboo-hurting-the-dignityandhealth-of-millions/9151 [Accessed 13 Jan 2021].

3 Buckley BS, Lapitan MCM. Prevalence of urinary and faecal incontinence and nocturnal enuresis and attitudes to treatment and help-seeking amongst a community-based representative sample of adults in the United Kingdom. Int J Clin Pract 2009;63:568-73.

4 Godfrey $\mathrm{H}$. Older people, continence care and catheters: dilemmas and resolutions. Br J Nurs 2008;17:S4-11.

5 Holroyd S. What can we do to improve the patient experience of continence care? J Comm Nurse 2015 https://www.jcn.co.uk/files/ downloads/articles/jcn-04-2015-15-what-can-we-do-to-improvepatient-experience-continence.pdf

6 Abrams P, Smith AP, Cotterill N. The impact of urinary incontinence on health-related quality of life (HRQL) in a real-world population of women aged 45-60 years: results from a survey in France, Germany, the UK and the USA. BJU Int 2015;115:143-52.

7 et alBillings JR, Alaszewski HP, Wagg A. Privacy and dignity in continence care project phase 2 . project report. centre for health 
services studies, Canterbury, 2009. Available: https://kar.kent.ac.uk/ 24801/1/Phase_2_Privacy_and_Dignity_in_Continence_Care_Report_ November_2009.pdf [Accessed 13 Jan 2021].

8 Borglin G, Hew Thach E, Jeppsson M, et al. Registered nurse's experiences of continence care for older people: a qualitative descriptive study. Int J Older People Nurs 2020;15:e12275.

9 Royal College of Physicians. All Party parliamentary group report: cost-effective commissioning for continence care, 2011. Available: https://www.rcplondon.ac.uk/projects/outputs/cost-effectivecommissioning-continence-care

10 Dealey C, Posnett J, Walker A. The cost of pressure ulcers in the United Kingdom. J Wound Care 2012;21:261-6.

11 Rantell A, Dolan L, Bonner L, et al. Minimum standards for continence care in the UK. Neurourol Urodyn 2016;35:400-6.

12 Ostaszkiewicz J. Reframing continence care in care-dependence. Geriatr Nurs 2017;38:520-6.

13 Healthcare Quality Improvement Partnership (HQIP) \& Royal College of Physicians. National audit of continence care: combined organisational and clinical report., 2010. Available: https://www.hqip. org.uk/wp-content/uploads/2010/01/2010-NACC-Annual-Repot.pdf [Accessed 13 Jan 2021].

14 Taylor DW, Cahill JJ. From stigma to the spotlight: a need for patientcentred incontinence care. Healthc Manage Forum 2018;31:261-4.

15 Harari D, Husk J, Lowe D, et al. National audit of continence care: adherence to National Institute for health and clinical Excellence (NICE) guidance in older versus younger adults with faecal incontinence. Age Ageing 2014;43:785-93.

16 Vethanayagam N, Orrell A, Dahlberg L, et al. Understanding helpseeking in older people with urinary incontinence: an interview study. Health Soc Care Community 2017;25:1061-9.

17 Yates A. Incontinence and associated complications: is it avoidable? Nurse Prescr 2017;15:288-95.

18 Age UK, The Urology Foundation, Marie Curie, Parkinson's UK, Alzheimer's Society, NIHR, D4D, JLA, Core BR. "My bladder and bowel own my life" - continence research: exploring the themes, needs and recommendations raised at a collaborative research workshop, 2018. Available: https://www.alzheimers.org.uk/sites/ default/files/2018-08/Incontinence\%20needs\%20-\%202018\% 20report\%20v9.pdf [Accessed 13 Jan 2021].

19 Wagg A, Potter J, Peel P, et al. National audit of continence care for older people: management of urinary incontinence. Age Ageing 2008;37:39-44.

20 Orrell A, McKee K, Dahlberg L, et al. Improving continence services for older people from the service-providers' perspective: a qualitative interview study. BMJ Open 2013;3:e002926.

21 Francis R. Report of the mid staffordshire NHS foundation trust public inquiry. stationery office, London, 2013. Available: http:// webarchive.nationalarchives.gov.uk/20150407084003/http://www. midstaffspublicinquiry.com/ [Accessed 13 Jan 2021].

22 Murphy C, Prieto J, Fader M. "It's easier to stick a tube in": a qualitative study to understand clinicians' individual decisions to place urinary catheters in acute medical care. BMJ Qual Saf 2015;24:444-50.
23 Booth J. Continence care is every nurse's business. Nurs Times 2013;109:12-16.

24 NHS England. Safe, compassionate care for frail older people using an integrated care pathway: practical guidance for commissioners, providers and nursing, medical and allied health professional leaders. NHS England, 2014. Available: https://www.england.nhs.uk/wpcontent/uploads/2014/02/safe-comp-care.pdf [Accessed 13 Jan 2021].

25 Bowling A. Research methods in health: investigating health and health services. Maidenhead, GB: Open University Press, 2014.

26 Silverman D. Interpreting qualitative data. London: Sage Publications Ltd, 2015.

27 King N. Using templates in the thematic analysis of texts. In: Cassell C, Symon G, eds. Essential guide to qualitative methods in organisational research. London: Sage, 2004: 256-70. https://www. researchgate.net/publication/224892354_Using_Templates_in_the Thematic_Analysis_of_Text

28 McCabe C. Nurse-patient communication: an exploration of patients experiences. J Clin Nurs 2004;13:41-9.

29 Redwood S, Simmonds B, Fox F, et al. Consequences of 'conversations not had': insights into failures in communication affecting delays in hospital discharge for older people living with frailty. J Health Serv Res Policy 2020;25:213-9.

30 Public Health England. Understanding and changing behaviours related to preventing catheter associated urinary tract infections: a strategic behavioural analysis. London: PHE, 2020. https://assets. publishing.service.gov.uk/government/uploads/system/uploads/ attachment_data/file/898207/PHE_CAUTI_Summary.pdf

31 NHS UK. Urinary catheter tools. Available: https://www.england. nhs.uk/patient-safety/urinary-catheter-tools/ [Accessed 17 Mar 2021].

32 Loveday HP, Wilson JA, Pratt RJ, et al. epic3: national evidencebased guidelines for preventing healthcare-associated infections in NHS hospitals in England. J Hosp Infect 2014;86:S1-70.

33 Public Health England. Preventing healthcare associated gramnegative bloodstream infections: an improvement resource. NHS improvement 2017 publication code: CG 28/17. Available: https://improvement.nhs.uk/resources/preventing-gram-negativebloodstream-infections/ [Accessed 13 Jan 2021].

$34 \mathrm{NHS}$. Are your patients feeling the pressure? Available: https://nhs. stopthepressure.co.uk/ [Accessed 13 Jan 2021].

$35 \mathrm{NHS}$ Improvement. Implementing the pressure ulcer framework in local reporting systems and reporting to NRLS. Available: https:// improvement.nhs.uk/documents/5114/Guidance_for_reporting pressure_ulcers.pdf [Accessed 13 Jan 2021].

36 McClurg D, Cheater FM, Eustice S, et al. A multi-professional UK wide survey of undergraduate continence education. Neurourol Urodyn 2013;32:224-9.

37 Nursing \& Midwifery Council. Future nurse: standards of proficiency for registered nurses. NMC, 2018. Available: https://www.nmc.org. uk/globalassets/sitedocuments/education-standards/future-nurseproficiencies.pdf [Accessed 1 Aug 2020]. 